\title{
Evaluation of the European Legislative Framework in Assessing the Vulnerability of Surface and Groundwater Bodies to Road Runoff
}

\author{
Tiago N. Martins (iD) ${ }^{*}$, Teresa E. Leitão (iD) ${ }^{2}$, Lian Lundy \\ ${ }^{1,2}$ Hydraulics and Environment Department, National Laboratory for Civil Engineering, Lisbon, Portugal \\ ${ }^{3}$ Urban Pollution Research Centre, Middlesex University, London, United Kingdom
}

Received 04 February 2020; accepted 31 March 2020

\begin{abstract}
This article presents an overview of the current European practices with regards to protecting surface water and groundwater bodies, in what concerns the application of legislation to protect water resources and to evaluate the vulnerability of water bodies to traffic related activities. This is achieved through the application of the EU Water Framework Directive and all Directives containing procedures to identify pressures affecting the state of water and environment, and the establishment of measures to ensure that all surface water and groundwater bodies achieve good status. A flowchart has been constructed to assist the assessment of the environmental legal constraints related to a road project. A combination of layers was integrated in GIS environment to address legislative needs and constraints, as well as the need to implement a risk assessment analysis of road runoff impact to surface and groundwater bodies.
\end{abstract}

Keywords: legislation review, guidelines, vulnerability, protection, road runoff pollution, flowchart, GIS.

\section{Introduction}

One of the main PROPER - Project Road runoff pollution management and mitigation of environmental risks (http://proper-cedr.eu/) tasks was to compile, review and critique existing datasets and tools to define surface and groundwater body vulnerability in relation to the polluting impacts of road construction and operation activities. This project was developed for the Conference of European Directors of Roads (CEDR).

Within this task, an evaluation of the non-technological mitigation measures was conducted by assessing legislative and non-legislative initiatives pertaining to the management of surface and groundwater bodies impacted on by traffic related activities. In fact, in European territories, the current international best practices with regard to protecting and enhancing surface water and groundwater bodies is to develop and implement an integrated water resources management strategy at a river basin scale through the application of the EU Water Framework Directive (EU WFD, 2000). Amongst other procedures, it requires Member States (MS) to identify pressures (e.g. point and diffuse source pollution, water abstraction, flow regulation, morphological pressure, land use patterns, and other pressures like invasive species) affecting the state of the water environment, and the establishment of 'Programmes of Measures' to ensure that all surface water and groundwater bodies achieve good status by 2027 . The cooperation at European level, towards the protection of water bodies may result in important steps to create joint guidelines for both construction and operation phase (Meland, 2016).

The development of a decision support tool to assess surface and groundwater vulnerability and impact of road pollution, therefore supporting the sustainable development of the road network, is viewed as an instrument to mitigate environmental impacts from roads, being therefore a response measure. Although data scarcity is a relevant problem (Yannapoulos et al., 2013), the EU has been developing platforms and create directives which result in standardized geographical mapping of the whole European territories within the community. This data may represent the basis of a common decision support system.

The aim of this article is to summarize the main legislation instruments that exist to impose specific constraints on the discharge of road-related pollutant emissions to receiving water bodies. This includes an assessment of EU WFD, EU Habitats Directive, EU Groundwater Directive, Natura 2000 areas, surface and groundwater (drinking water) protection zones, and non-legislative initiatives pertaining to the management of surface and groundwater bodies impacted on by traffic related activities.

*Corresponding author. E-mail: tmartins@lnec.pt 


\section{Legislative frameworks for European Union}

In order to facilitate the overview of legislative frameworks, the evaluation was structured using the conceptual index framework of DPSIR (driver-pressure-state-impact-response) initially proposed by OECD (in Shah, 2000). This framework helps structuring all important datasets and approaches leading to the evaluation of vulnerability and impacts, which will serve as the basis for the definition of programmes of measures, i.e., the responses. In the process the road is considered to be the driver and the pressures are the contaminant loads associated with highway runoff or aerial dispersion (vehicle activities, road surface material and vehicle emissions). The status concerns the quality of soil and water. The magnitude of the impact of highway runoff on receiving waters depends on several aspects concerning the flow regime of receiving water, infiltration facility, depth to groundwater, and different land cover data sets. Some of these sensitive areas have been legislated as protected areas (e.g. flood risk zones, sensitive zones, vulnerable areas) imposing specific constraints to the discharge of road-related pollutant emissions in receiving water bodies.

\subsection{Legislative frameworks related to hazards (pressures)}

\section{Water Framework Directive}

The Water Framework Directive (WFD, Directive 2000/60/EC on "establishing a framework for Community action in the field of water policy"), published in December 2000, aims to establish a framework for the protection of inland surface waters, transitional waters, coastal waters as well as groundwater. Its objective is to prevent further deterioration, and protect and enhance the status of aquatic ecosystems, by promoting sustainable water use based on a long-term perspective. This implies the implementation of measures for the progressive reduction of discharges, emissions and losses of priority substances to prevent further pollution of water. The hazards considered within the context of PROPER are "highway discharges" (Revitt et al., 2018).

The WFD presents an indicative list of what, in general, are considered the main groups of pollutants in water. Some of these are toxic while others are nutrients or substances causing oxygen depletion. In particular, a number of priority substances have been given special attention. This is the List of Priority Substances, which includes some hazardous substances, in the field of water policy defined in Annex X of the WFD and reviewed in the Directive 2013/39/EU ("amending Directives 2000/60/EC and 2008/105/EC as regards priority substances in the field of water policy"). Some of these are typical traffic and road pollutants, such as Polycyclic Aromatic Hydrocarbons (PAH) and heavy metals.

Concerning pressures, the WFD states that a summary of the significant pressures on the status of surface water and groundwater should be ascertained during the River Basin Management Plans (RBMP) (WFD, Annex VII, A.2.), including an estimation of point and diffuse pollution sources, their concentrations and loads, in order to ensure the implementation of the relevant Emission Limit Values (ELV).

WFD Annex IX started to define ELV and environmental quality based on several directives. Directive 2008/105/EC "on environmental quality standards in the field of water policy" has "amended and subsequently repealed Council Directives 82/176/EEC (Mercury Discharges), 83/513/EEC (Cadmium Discharges), 84/156/EEC (Mercury Directive), 84/491/EEC (Hexachlorocyclohexane Discharges), 86/280/EEC (Dangerous Substance Discharges), thus also amending Directive 2000/60/EC of the European Parliament and of the Council. Directive 2013/39/EU amended Directives 2000/60/EC and 2008/105/EC as regards priority substances in the field of water policy".

Other ELV are stated in other directives (as stated in WFD Article 16): these include Directive 2010/75/EU "on industrial emissions (integrated pollution prevention and control)", Directive 91/271/EEC "concerning urban waste water treatment" and Directive 91/676/EEC “concerning the protection of waters against pollution caused by nitrates from agricultural sources".

A summary of the controls adopted for point source discharges with an impact on the status of water is made in accordance with the provisions of WFD Article 11(3)(g) and 11(3)(i). WFD Point 3 of Article 11 establishes basic measures that, among others, define minimum requirements to be complied for:

- (g) Point source discharges liable to cause pollution, a requirement for prior regulation, such as a prohibition on the entry of pollutants into water, or for prior authorisation, or registration based on general binding rules, laying down emission controls for the pollutants concerned, including controls in accordance with WFD Articles 10 and 16.

-(i) Any other significant adverse impacts on the status of water identified under WFD Article 5 (Characteristics of the river basin district, review of the environmental impact of human activity and economic analysis of water use) and Annex II (Characterisation of surface water body types), in particular measures to ensure that the hydromorphological conditions of the water bodies are consistent with the achievement to require ecological status or good ecological potential for water bodies designated as artificial or heavily modified. 
Concerning the point source emissions, Article 10 establishes that MS shall ensure implementation of emission controls in all discharges into surface water, based on best available technologies or in relevant ELV set out in the Directives referred to in Section 2.1.2. For diffuse source emissions, Article 10 also establishes that MS shall ensure that the controls, include, when necessary, the best environmental practices.

Also, Article 16 states that the European Parliament and the Council shall adopt specific measures against pollution of water by individual pollutants or groups of pollutants presenting a significant risk to or via the aquatic environment, including risks to waters used for the abstraction of drinking water. For those pollutants, measures shall be aimed at the progressive reduction and, for priority hazardous substances, at the cessation or phasing-out of discharges, emissions and losses.

The identification and prioritization for action of these substances (defined in Annex X of the WFD and replaced by Annex II of Directive 2013/39/EU) is based on evidence regarding the intrinsic hazard of the substance concerned, and in particular its aquatic ecotoxicity and human toxicity via aquatic exposure routes. Evidence from monitoring of widespread environmental contamination, and other proven factors which may indicate the possibility of widespread environmental contamination, such as production or use volume of the substance concerned, and use patterns are also taken into account.

The regulatory regime consists of a system of authorization, together with environmental monitoring to ensure that pollution by dangerous substances does not exceed Environmental Quality Standards (EQS) in the water (defined in Annex X of the WFD and reviewed in the Directive 2013/39/EU). Directive 2013/39/EU, on environmental quality standards in the field of water policy, defines in Annex I the EQS for priority substances and certain other pollutants and in Annex II presents the list of priority substances in the field of water policy.

\section{Groundwater Directive}

The Groundwater Directive 2006/118/EC “on the protection of groundwater against pollution and deterioration" is also an issue for the WFD. Environmental quality standards have been established, by MS, for individual pollutants or groups of pollutants, for those water bodies identified as being at risk of failing the environmental quality objectives to or via the aquatic environment.

Road runoff discharges can also affect groundwater and its protection depends on the specific risks identified. For that assessment, all MS are required to carry out an initial characterisation of groundwater bodies to assess their uses and the degree to which they are at risk of failing to meet the objectives established under Article 4. This analysis may employ existing hydrological, geological, pedological, land use, discharge, abstraction and other data but shall identify:

- The location and boundaries of the groundwater body or bodies.

- The pressures to which the groundwater body or bodies are liable to be subject.

- The general character of the overlying strata in the catchment area from which the groundwater body receives its recharge.

- Those groundwater bodies for which there are directly dependent surface water ecosystems or terrestrial ecosystems.

Following this initial characterisation, MS are required to carry out further characterisation of those groundwater bodies or groups of bodies which have been identified as being at risk in order to establish a more precise assessment of the significance of such risk and the identification of any measures to be required under Article 11. Accordingly, this characterisation shall include relevant information on the impact of human activity and, where relevant, information on:

- Geological characteristics of the groundwater body including the extent and type of geological units.

- Hydrogeological characteristics of the groundwater body including hydraulic conductivity, porosity and confinement.

- Characteristics of the superficial deposits and soils in the catchment from which the groundwater body receives its recharge, including the thickness, porosity, hydraulic conductivity, and absorptive properties of the deposits and soils.

- Stratification characteristics of the groundwater within the groundwater body.

- An inventory of associated surface systems, including terrestrial ecosystems and bodies of surface water, with which the groundwater body is dynamically linked.

- Estimates of the directions and rates of exchange of water between the groundwater body and associated surface systems.

- Sufficient data to calculate the long term annual average rate of overall recharge.

- Characterisation of the chemical composition of the groundwater, including specification of the contributions from human activity, which in PROPER project the human activities contribution refers to road runoff. 


\subsection{Legislative frameworks related to the magnitude of impacts (state and impact)}

\section{Water Framework Directive - Water bodies status}

The magnitude of an impact depends on several factors related to the intrinsic vulnerability of the receiving media, but also on the state of that media before the discharge. If the state of the receiving water body is poor, it is necessary to analyse if the discharge could have significant adverse effects. To evaluate the surface and groundwater status, Article 8 of the WFD determines that all MS shall ensure the establishment of monitoring programmes for all water status bodies in order to create a coherent and comprehensive overview within each river basin district. WFD Annex $\mathrm{V}$ defines the elements, methodologies and the maps requested from the results of the monitoring programmes.

\section{Water Framework Directive - Protected areas for abstraction of water intended for human consumption}

The areas which have been designated as requiring special protection under specific European Community legislation, either for the protection of surface water and groundwater or for the conservation of habitats and species directly depending on water, are those in which discharges are not allowed if the risk assessment shows unacceptable environmental contamination. MS shall ensure the establishment of their inventories.

Identification and mapping of protected areas are defined by Article 6 and Annex IV of the WFD, including the areas designated for the abstraction of water intended for human consumption under Article 7.

MS are required to identify, within each river basin district, all bodies of water used for the abstraction of water intended for human consumption providing more than $10 \mathrm{~m}^{3}$ a day, as an average, or serving more than 50 persons, as well as those bodies of water intended for such future use. MS shall ensure the necessary protection of those water bodies, the identification of pollution problems and the substances causing them, and the establishment of quality standards. MS may establish safeguard zones or wellhead protection areas (WHPA) for those bodies of water.

A WHPA is the surface and subsurface area around a well for which limits are defined to assure that potential bacteriological contaminants, after reaching groundwater inside or outside protection zones, become harmless before reaching the well. Groundwater resources polluting activities are prohibited or restricted inside the WHPA. Different member countries may have their own specific interpretations.

\section{Water Framework Directive - Protected aquatic ecosystems}

The register of protected areas within each river basin is required under Article 6 of the WFD and includes the areas designated for the protection of economically significant aquatic species. Direct discharges into these areas depend on risk assessment results.

\section{Nitrates Directive (nutrient-sensitive or vulnerable zones)}

The Nitrates Directive (91/676/EEC) aims to prevent and reduce water pollution caused or induced by nitrates from agricultural sources (Article 1). It defines vulnerable zones (Article 3) as waters affected by pollution and waters which could be affected by pollution - by monitoring nitrate concentrations in freshwaters over a period of one year, for four consecutive years and reporting to the European Commission the location and criteria of identification.

Within the goal of providing all waters with a general level of protection against pollution, MS have to establish codes of good agricultural practice, to be implemented by farmers on a voluntary basis and, if necessary, with a training and information programme for farmers promoting application of good agricultural practice codes (Article 4). MS are required to review and, if necessary, revise their action programmes, including any additional measures, at least every four years. The European Commission (EC) should be informed of any changes to the action programmes.

This Directive makes no specific reference to road runoff pollution. The vulnerable zones defined by the criteria established by the Directive refer to low quality status and nutrient sensitive water bodies and therefore another pressure, such as that resulting from road runoff pollution, should be avoided or heavily mitigated so it does not hinder the effect of applied measures for protection.

\section{Urban Waste Water Directive (sensitive areas)}

The Urban Waste Water Directive (91/271/EEC; 98/15/EC) (UWWD) concerns the collection, treatment and discharge of urban waste water (domestic waste water or the mixture of domestic waste water with industrial waste water and/or runoff rain water) and the treatment and discharge of urban waste water from certain industrial sectors. The main objective is the protection of the environment from the adverse effects of the above mentioned waste water discharges. The Directive outlines the appropriate treatment requirements prior to discharges in sensitive areas, defined as areas particularly exposed to eutrophication (enrichment of water by nutrients, especially compounds of nitrogen and/or phosphorus, causing an accelerated growth of algae and higher forms of plant life to produce an undesirable disturbance to the balance of organisms present in the water and to the quality of the water concerned).

Article 5 defines the requirements of urban waste water discharge into sensitive areas:

- "MS shall ensure that urban waste water entering collecting systems shall, before discharge into sensitive areas, be subject to more stringent treatment [...] at the latest for all discharges from agglomerations of more than 10000 p.e.". 
- "Discharges from urban waste water treatment plants described in paragraph 2 shall satisfy the relevant requirements of Annex I B".

- "Alternatively, requirements for individual plants set out in paragraphs 2 and 3 above need not apply in sensitive areas where it can be shown that the minimum percentage of reduction of the overall load entering all urban waste water treatment plants in that area is at least $75 \%$ for total phosphorus and at least $75 \%$ for total nitrogen".

- "Discharges from urban waste water treatment plants which are situated in the relevant catchment areas of sensitive areas and which contribute to the pollution of these areas shall be subject to paragraphs 2, 3 and 4".

Table 1 of Annex 1 of UWWD defines the requirements for discharges from urban waste water treatment plants for Biochemical Oxygen Demand (BOD), Chemical Oxygen Demand (COD) and Total Suspended Solids (TSS). Table 2 of the same annex defines requirements for discharges from urban waste water treatment plants to sensitive areas which are subject to eutrophication, concerning total phosphorus and total nitrogen concentrations. There is no explicit reference to road runoff impact or treatment specifications in this Directive.

\section{Natura 2000 (areas designated for the protection of habitats or species)}

The Natura 2000 Directive (92/43/EEC) aims to contribute towards ensuring bio-diversity through the conservation of natural habitats and the populations of species of wild fauna and flora in the European Territory. This should be achieved by defining measures designed to maintain or restore, at favourable conservation status, natural habitats and species of wild fauna and flora, taking into account economic, social and cultural requirements and regional and local characteristics.

The sites are defined based on criteria and relevant scientific information describing the natural habitat types and which species are native to the site. For special areas of conservation, MS shall establish the necessary conservation measures involving, if needed, appropriate management plans specifically designed for the sites or integrated into other development plans, and appropriate statutory, administrative or contractual measures which correspond to the ecological requirements of the natural habitat types and species present in the sites. The MS shall also take appropriate steps to avoid, in the special areas of conservation, the deterioration of natural habitats and the habitats of species as well as disturbance of the species for which the areas have been designated.

The Directive defines that any plan or project not directly connected with or necessary to the management of the site but likely to have a significant effect thereon, either individually or in combination with other plans or projects, shall be subject to appropriate assessment of its implications for the site in view of the site's conservation objectives. The competent national authorities shall agree to the plan or project only after having ascertained that it will not adversely affect the integrity of the site concerned and, if appropriate, after having obtained the opinion of the general public. On the other hand, if in spite of a negative assessment of the implications for the site and in the absence of alternative solutions, a plan or project must nevertheless be carried out for imperative reasons of overriding public interest, including those of a social or economic nature. The MS are required to take all compensatory measures necessary to ensure that the overall coherence of Natura 2000 is protected.

In the road runoff pollution context, Revitt et al. (2018) clearly states that highway runoff can impact negatively on the chemical and ecological status of receiving waters and ecosystems. Research has shown impacts on a range of species and allowed for the conclusion that, in addition to road construction and operation affecting ecosystems in a variety of ways, highway discharges can be a main driver in ecological impacts due to changes in water quality. Therefore, the water bodies within the areas defined by this Directive which are exposed to road runoff should have a risk assessment.

\section{Flood Risks Management Directive}

The Flood Risks Management Directive (2007/60/EC) establishes a framework for the assessment and management of flood risks, aiming at the reduction of the adverse consequences for human health, the environment, cultural heritage and economic activity associated with floods in the European Community. Article 1 of the Directive (following Water Framework Directive (2000/60/EC) Article 3) concerns the coordination of administrative arrangements within river basin districts. Article 4 requires that MS shall, for each river basin district, unit of management, or the portion of an international river basin district lying within their territory, undertake a preliminary flood risk assessment based on available or readily derivable information, such as records and studies on long term developments. In particular impacts of climate change on the occurrence of floods should be considered.

No reference is made in this Directive directly to road runoff pollution, but road sections prone to the effects of flooding (that are within Areas with Potential Significant Flood Risk) may result in increased flow volumes entering the receiving water, with contaminants mobilization from the road surface/treatment systems to nearby water bodies.

\subsection{Legislative frameworks related to the measures (response)}

\section{Water Framework Directive - Controls adopted for point source discharges and other activities}

The Article 11 of the WFD (2000/60/EC) defines the programs of measures necessary to bring the water bodies to required good status. For diffuse sources liable to cause pollution, like road runoff, WFD considers measures to 
prevent or control the input of pollutants. In the context of road runoff pollution and from the DPSIR Response perspective, the evaluation of impact in the discharge area may be different from what was presented in the other components. One has to consider the composition of the road runoff discharge through the emission limit values, to ensure that no significant impact occurs. This is not the purpose of this article.

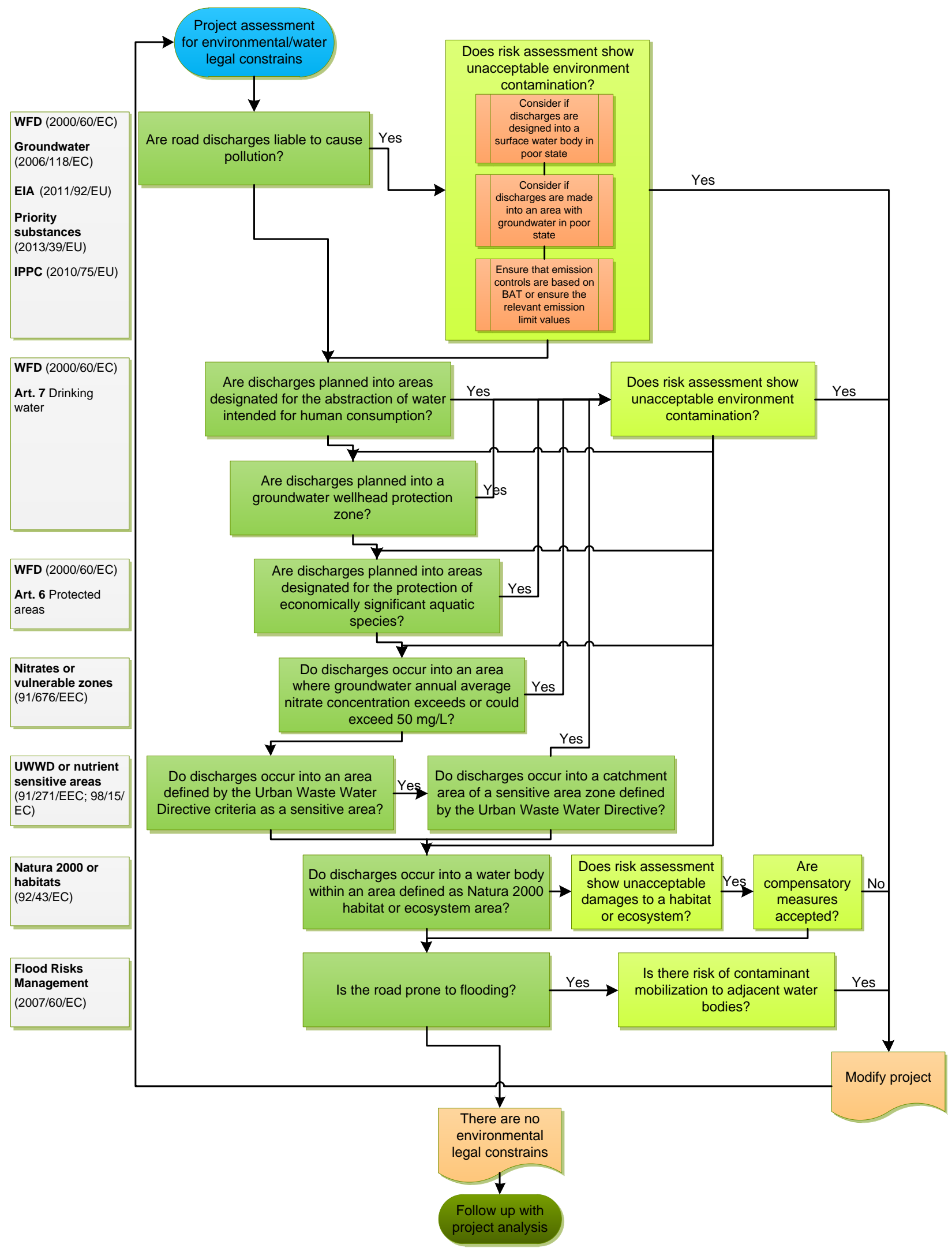

Figure 1. Flowchart for the assessment of a road project aiming to analyse environmental/water legal constrains 


\section{Approaches for integrating legislative constraints}

Based on the analysis of the common European legislative framework, Figure 1 presents a flowchart for the assessment of a road project taking into account the relevant environmental legal constraints. The conceptualization of this flowchart, which later will be the basis for mapping procedures, is basically a Yes/No set of questions for each Directive. An example of implementation, both in the flowchart and GIS environment, is described in the next two bullets considering the constraints posed by the Groundwater Directive as example. The information gathered for each case-study area is considered by using:

- The flowchart question "Are road discharges liable to cause pollution?" If the answer is No, then the next question should follow. If the answer is Yes, a risk assessment should be done to show if unacceptable environment contamination is predicted (cf. Environmental Impact Assessment Directive [EIA] 2011/92/EU). This should take into account if the discharges are into a surface or groundwater body in a poor state, and ensure that emission controls are based on Best Available Technology (BAT) or the relevant ELV are considered.

- In GIS, the shapefiles produced by each MS and submitted to the Water Information System for Europe (WISE) should be considered providing prior information for the risk assessment:

- existing diffuse pollution emissions;

- existing point pollution emissions (which include point source road runoff discharges).

This will allow determining existing pressures and combined impacts if a new road discharge is proposed into receiving water bodies. For the Nitrates Directive the procedure is similar, as the information gathered for each casestudy area can be considered by using:

- The flowchart question "Do discharges occur into an area where groundwater annual average nitrate concentration exceeds or could exceed $50 \mathrm{mg} / \mathrm{L}$ ?" If the reply is No, then the next question should follow. If the answer is Yes, then discharges should not be allowed if the risk assessment proves unacceptable environmental contamination, since the area is declared a vulnerable zone by the Nitrates Directive.

- In GIS, the vulnerable zone shapefiles, produced by each MS and submitted to the WISE, should be considered, and discharges should not be allowed if the risk assessment proves the existence of unacceptable environmental contamination.

The geographical information gathered, produced within each previously referred legal framework, is the basis of the application of the flowchart presented in Figure 1. The use of GIS platforms is essential as it allows the user to visually validate each sequential question posed in the flowchart. Standardization of the geographical information that is already available in EU platforms, such as WISE, is fundamental to the implementation of automatic processes for decision making by creating tools within GIS platforms. These layers of information, and the sequence of analysis presented in the flowchart, can represent a primary structure in a decision support system to allow user visualization of data by producing maps resulting from simple intersection processes. This shows sensitive, vulnerable or protected areas requiring further risk assessment for the decision process.

To illustrate the application of GIS, having the flowchart as guideline, a Portuguese highway segment (Autoestrada 6 - A6) has been selected. The set of information layers are integrated into a map dataset as presented in Figure 2. The map presented was developed in open-source QGIS platform. Following the flowchart sequence, a set of questions can be answered, as described in Table 1 and direct visualization provided of possible highway segment intersections with specific areas defined by legal constraints.

Table 1. Set of questions and answers resulting from the flowchart analysis with visual validation through GIS

\begin{tabular}{|c|c|c|}
\hline Legal framework & Question & Answer \\
\hline $\begin{array}{l}\text { WFD }(2000 / 60 / E C) \\
\text { Groundwater }(2006 / 118 / E C) \\
\text { EIA }(2011 / 92 / E U) \\
\text { Priority substances } \\
\text { (2013/39/EU) } \\
\text { IPPC (2010/75/EU) }\end{array}$ & $\begin{array}{l}\text { Are road discharges liable to cause pollution? } \\
\text { Are poor state surface water or groundwater body } \\
\text { intersected? }\end{array}$ & $\begin{array}{l}\text { Yes. Risk assessment } \\
\text { may be necessary in } \\
\text { those areas }\end{array}$ \\
\hline $\begin{array}{l}\text { WFD }(2000 / 60 / \mathrm{EC}) \\
\text { Art. } 7 \text { Drinking water }\end{array}$ & $\begin{array}{l}\text { Are discharges planned into areas designated for the } \\
\text { abstraction of water intended for human consumption? } \\
\text { Are discharges planned into a groundwater wellhead } \\
\text { protection zone? }\end{array}$ & No \\
\hline $\begin{array}{l}\text { WFD }(2000 / 60 / \mathrm{EC}) \\
\text { Art. } 6 \text { Protected areas }\end{array}$ & $\begin{array}{l}\text { Are discharges planned into areas designated for the } \\
\text { protection of economically significant aquatic species? }\end{array}$ & $\begin{array}{l}\text { Yes. Risk assessment } \\
\text { may be necessary in } \\
\text { those areas }\end{array}$ \\
\hline
\end{tabular}


End of Table 1

\begin{tabular}{|l|l|l|}
\hline \multicolumn{1}{|c|}{ Legal framework } & \multicolumn{1}{c|}{ Question } & \multicolumn{1}{c|}{ Answer } \\
\hline $\begin{array}{l}\text { Nitrates or vulnerable zones } \\
(91 / 676 / \mathrm{EC})\end{array}$ & $\begin{array}{l}\text { Do discharges occur into an area where groundwater } \\
\text { annual average nitrate concentration exceeds or could } \\
\text { exceed } 50 \mathrm{mg} / \mathrm{L} ?\end{array}$ & $\begin{array}{l}\text { Yes. Risk assessment } \\
\text { may be necessary in } \\
\text { those areas }\end{array}$ \\
\hline $\begin{array}{l}\text { UWWD or nutrient sensitive } \\
\text { areas }(91 / 271 / \mathrm{EEC} ; 98 / 15 / \mathrm{EC})\end{array}$ & $\begin{array}{l}\text { Do discharges occur into an area defined by the UWWD } \\
\text { criteria as a sensitive area? }\end{array}$ & \multicolumn{1}{c|}{ No } \\
\hline $\begin{array}{l}\text { Natura 2000 or habitats } \\
(92 / 43 / \mathrm{EEC})\end{array}$ & $\begin{array}{l}\text { Do discharges occur into a water body within an area } \\
\text { defined as Natura } 2000 \text { habitat or ecosystem area? }\end{array}$ & $\begin{array}{l}\text { Yes. Risk assessment } \\
\text { may be necessary in } \\
\text { those areas }\end{array}$ \\
\hline $\begin{array}{l}\text { Flood Risks Management } \\
(2007 / 60 / \mathrm{EC})\end{array}$ & Is the road prone to flooding? & No \\
\hline
\end{tabular}

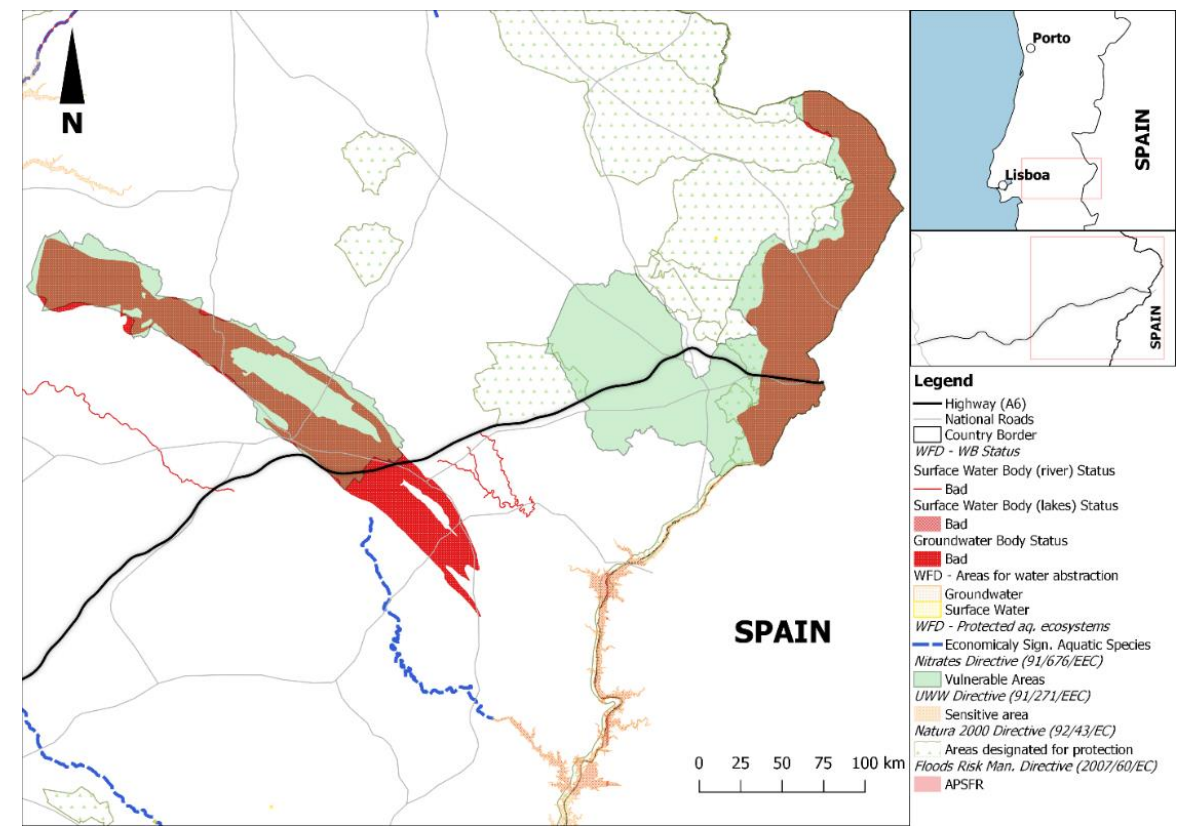

Figure 2. Map with geographical dataset produced within the legal framework concerning environmental/water legal constrains

The main result is a map that supports decision making with regard to the placement of discharges along the highway, as presented in Figure 3.

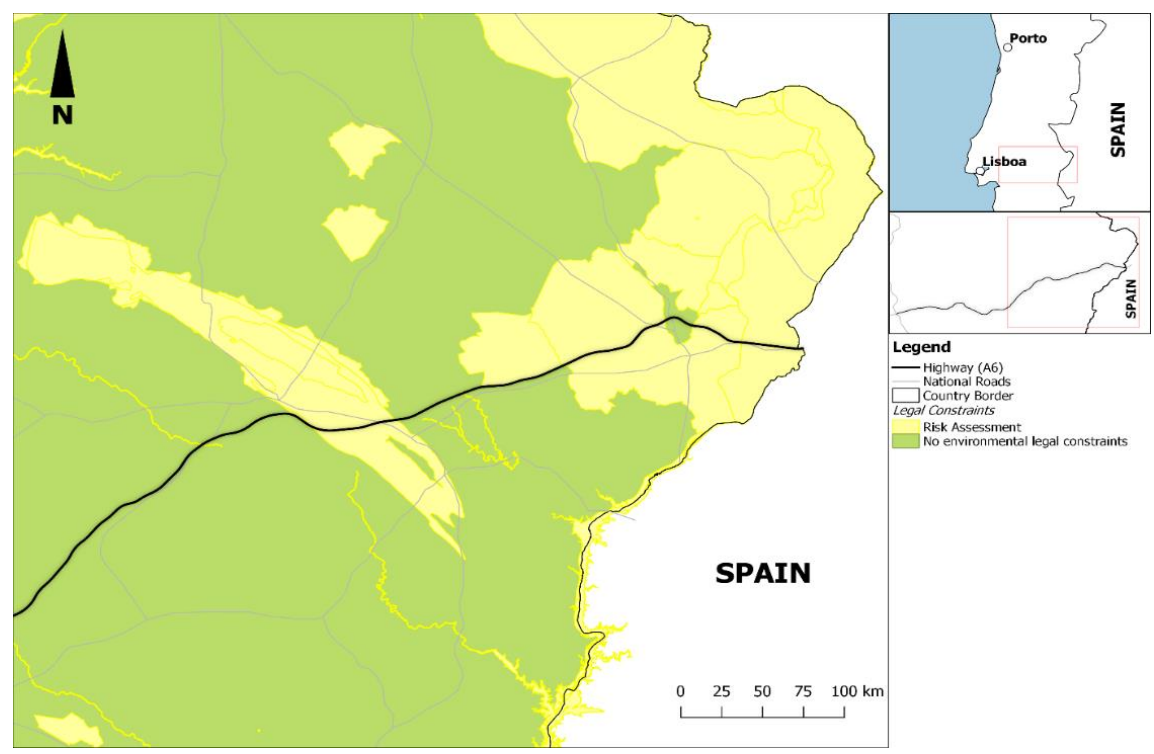

Figure 3. Final map presenting areas where risk assessment may be necessary if discharges are to be allowed 


\section{Conclusions}

The EU Water Framework Directive and other Directives designed to mitigate pressures affecting the state of water and environment are briefly discussed and an approach for the integration of all relevant environmental legislative constraints to a road project has been defined through a flowchart that guides the use of a GIS procedure with a combination of layers to address legislative needs and constraints to protect surface and groundwater bodies from impacts caused by traffic-related activities. The flowchart can assist the determination of the risk assessment associated with roads on a European scale based on a set of questions and answers resulting from its analysis. This procedure may be part of a decision support tool, aided by geographical information systems, transferable for other case-study sites to assess the vulnerability of surface water and groundwater to road-related pollution activities.

\section{Acknowledgements}

The authors would like to acknowledge Ana Telhado (Portuguese Environment Agency, APA), Mike Revitt (Middlesex University, MU), Mihael Brenčič (University of Ljubljana, UL), Roman Ličbinský and Vilma Jandova (Centrum Dopravního Výzkumu, CDV), Rianne Dröge (Nederlandse Organisatie voor ToegepastNatuurwetenschappelijk, TNO), Pierre-Emmanuel Peyneau (l'Institut Français des Sciences et Technologies des Transports, de l'Aménagement et des Réseaux, IFFSTAR) for their contribute in providing information from national and european frameworks.

\section{Funding}

The work presented was developed within the CEDR Transnational Road Research Programme Call 2016, Environmentally Sustainable Roads, Surface- and Groundwater Quality, Topic A, "PROJECT PROPER" under the Public service contract ARVODI-2014 (The Netherlands).

\section{Author contributions}

Teresa E. Leitão and Tiago N. Martins gathered information within the European Framework. The flowchart was developed by Tiago N. Martins and Teresa E. Leitão with inputs from Lian Lundy. Teresa E. Leitão structured the report from which this article is based and contacted project partners in order to receive feedback about the flowchart structure. All authors reviewed the article.

\section{Disclosure statement}

The authors declare that they don't have any competing financial, professional, or personal interests from other parties.

\section{References}

European Union. (2020). The European Parliament and of the Council of 23 October 2000 establishing a framework for Community action in the field of water policy (Directive 2000/60/EC). https://eur-lex.europa.eu/legal-content/EN/TXT/?uri=CELEX\%3A32000L0060

European Union. (2006). The European Parliament and of the Council of 12 December 2006 on the protection of groundwater against pollution and deterioration (Directive 2006/118/EC). https://eur-lex.europa.eu/legal-content/EN/TXT/?uri=CELEX\%3A32006L0118

European Union. (2007). The European Parliament and of the Council of 23 October 2007 on the assessment and management of flood risks (Directive 2007/60/EC). https://eur-lex.europa.eu/legal-content/EN/TXT/?uri=celex:32007L0060

European Union. (2008). The European Parliament and of the Council of 16 December 2008 on environmental quality standards in the field of water policy (Directive 2008/105/EC). https://eur-lex.europa.eu/eli/dir/2008/105/oj

European Union. (2010). The European Parliament and of the Council of 24 November 2010 on industrial emissions (integrated pollution prevention and control) (Directive 2010/75/EU). https://eur-lex.europa.eu/legal-content/EN/TXT/?uri=CELEX\%3A32010L0075

European Union. (2011). The European Parliament and of the Council of 13 December 2011 on the assessment of the effects of certain public and private projects on the environment text with EEA relevance (Directive 2011/92/EU). https://eurlex.europa.eu/legal-content/EN/TXT/?uri=CELEX\%3A32011L0092

European Union. (2013). The European Parliament and of the Council of 12 August 2013 amending Directives 2000/60/EC and 2008/105/EC as regards priority substances in the field of water policy text with EEA relevance (Directive 2013/39/EU). https://eur-lex.europa.eu/eli/dir/2013/39/oj

European Union. (1991a). 21 May 1991 concerning urban waste-water treatment (Directive 91/271/EEC). https://eur-lex.europa.eu/legal-content/EN/TXT/?uri=CELEX\%3A31991L0271 
European Union. (1991b). 12 December 1991 concerning the protection of waters against pollution caused by nitrates from agricultural sources (Directive 91/676/EEC). https://eur-lex.europa.eu/legal-content/EN/TXT/?uri=celex\%3A31991L0676

European Union. (1992). 21 May 1992 on the conservation of natural habitats and of wild fauna and flora (Directive 92/43/EEC). https://eur-lex.europa.eu/legal-content/EN/TXT/?uri=celex\%3A31992L0043

Meland, S. (2016, April). Management of contaminated runoff water: current practice and future research needs. Secretariat of the Conference of European Directors of Roads (CEDR).

Revitt, M., Ellis, B., \& Lundy, L. (2018). Deliverable 2.1 A review of current knowledge on the vulnerability of European surface water and groundwater to road related pollution, together with a critique of related assessment tools (CEDR PROPER Project). Middlesex University, UK.

Shah, R. (2000, April 25-28). International frameworks of environmental statistics and indicators. Paper presented at the Proceedings of the Inception Workshop on the Institutional Strengthening and Collection of Environment Statistics, Samarkand, Uzbekistan. United Nations Economic and Social Commission for Asia and the Pacific. http://www.unescap.org/stat/envstat/stwes-015.pdf

Yannapoulos, S., Basbas, S., \& Giannopoulos, L. (2013). Water bodies pollution due to highways stormwater runoff: Measures and legislative framework. Global Nest Journal, 15(1), 85-92. 